\title{
Paired Box Protein Pax-8
}

National Cancer Institute

\section{Source}

National Cancer Institute. Paired Box Protein Pax-8. NCI Thesaurus. Code C97690.

Paired box protein Pax-8 (450 aa, $\sim 48 \mathrm{kDa}$ ) is encoded by the human PAX8 gene. This protein is involved in the differentiation of thyroid follicular cells. 